\title{
Photoluminescence as a Valuable Tool in the Optical Characterization of Acetaminophen and the Monitoring of Its Photodegradation Reactions
}

\author{
Monica Daescu ${ }^{1,2}{ }^{\mathbb{D}}$, Adelina Matea ${ }^{1}$, Catalin Negrila ${ }^{3}$, Constantin Serbschi ${ }^{4}$, Alina C. Ion ${ }^{2}$ \\ and Mihaela Baibarac $1, *$ \\ 1 Laboratory of Optical Processes in Nanostructured Materials, National Institute of Materials Physics, \\ Atomistilor Street 405A, P.O. Box MG-7, 077125 Bucharest, Romania; monica.daescu@infim.ro (M.D.); \\ adelina.udrescu@infim.ro (A.M.) \\ 2 Faculty of Applied Chemistry and Materials Science, University Politehnica of Bucharest, Gh. Polizu St 1-7, \\ 011061 Bucharest, Romania; ac_ion@yahoo.com \\ 3 Nanoscale Condensed Matter Laboratory, National Institute of Materials Physics, Atomistilor Street 405A, \\ P.O. Box MG-7, 077125 Bucharest, Romania; catalin.negrila@infim.ro \\ 4 Bioelectronic SRL, Cercelus Street, no.54, Ploiesti, Romania; bioelectronic90@yahoo.com \\ * Correspondence: barac@infim.ro; Tel.: +40-21-369-0170
}

Academic Editors: Urszula Guzik and Danuta Wojcieszyńska

Received: 4 September 2020; Accepted: 6 October 2020; Published: 7 October 2020

\begin{abstract}
In this work, new evidence for the photodegradation reactions of acetaminophen (AC) is reported by photoluminescence (PL), Raman scattering and FTIR spectroscopy. Under excitation wavelength of $320 \mathrm{~nm}$, AC shows a PL band in the spectral range of 340-550 nm, whose intensity decreases by exposure to UV light. The chemical interaction of AC with the $\mathrm{NaOH}$ solutions, having the concentration ranging between 0.001 and $0.3 \mathrm{M}$, induces a gradual enhancement of the photoluminescence excitation (PLE) and PL spectra, when the exposure time of samples at the UV light increases until $140 \mathrm{~min}$, as a result of the formation of p-aminophenol and sodium acetate. This behavior is not influenced by the excipients or other active compounds in pharmaceutical products as demonstrated by PLE and PL studies. Experimental arguments for the obtaining of p-aminophenol and sodium acetate, when $\mathrm{AC}$ has interacted with $\mathrm{NaOH}$, are shown by Raman scattering and FTIR spectroscopy.
\end{abstract}

Keywords: acetaminophen; photodegradation; UV light

\section{Introduction}

Acetaminophen (AC) is an active compound of different drugs marketed under the name of Paracetamol, Theraflu, Coldrex, Parasinus, Algopirin, and so on. The therapeutic effects for which $\mathrm{AC}$ is administered are: (i) the reduction of headaches during migraines [1]; (ii) the diminution of kidney stone-induced pain [2]; (iii) osteoarthritis which involves the pain at the hip, knee and hands [3]; (iv) the cutting down of the pain resulting after dental procedures [4]; (v) fighting fever [5] and recently in coronavirus disease (Covid-19) [6]. The most important adverse effects of AC reported until now consist of the generation of liver damage [7,8]. The use of a dose of AC higher than $4000 \mathrm{mg}$ per day induces the appearance of acute liver failure, which then leads to the death of the un-treated patients [9].

For the quantitative determination of paracetamol in biological fluids and tablets, a sustained effort was carried out in the development of analytical techniques such as high-performance liquid chromatography (HPLC) [10], UV-VIS absorption spectroscopy [11], surface enhanced Raman scattering [12], cyclic voltammetry [13], square-wave adsorptive anodic stripping voltammetry [14], 
chronoamperometry [15], differences pulse voltammetry [16], and so on. The drug stability is an important topic with consequences for its therapeutic effect. The tests of the drug stability include the reactions of these with acids and alkaline solution. The AC degradation was studied for the first time in 2013 [17], by the UV-VIS absorption spectroscopy studies, which were validated by HPLC. According to Feng et al. (2013) [17], the alkaline degradation of AC leads to the formation of p-aminophenol, a compound with high toxicity, which was highlighted by UV-VIS spectroscopy over $24 \mathrm{~h}$. In contrast with this progress, we demonstrated that an alternative method to assess the AC degradation in the presence of alkaline solution may be photoluminescence (PL). Both PL and photoluminescence excitation (PLE) are two methods which will allow highlighting the degradation of AC in sodium hydroxide $(\mathrm{NaOH})$ in a shorter time than that reported by UV-VIS absorption spectroscopy. In addition, new evidence for the generation of $\mathrm{p}$-aminophenol and sodium acetate as a result of the interaction of AC with $\mathrm{NaOH}$ will be shown by Raman scattering and FTIR spectroscopy.

\section{Materials and Methods}

\subsection{Materials}

The chemical compounds, namely $\mathrm{AC}$ and $\mathrm{NaOH}$, were purchased from Sigma-Aldrich. The drugs containing $\mathrm{AC}$ as an active compound, marked under the name Paracetamol (containing $500 \mathrm{mg}$ AC, Magistra C\&C), Parasinus (having $500 \mathrm{mg}$ AC, Europharm) and Pararemin (having $250 \mathrm{mg}$ AC, Polisano), were bought from a local pharmacy. The composition of a tablet of: (i) Paracetamol from Magistra C\&C contains $500 \mathrm{mg}$ AC and excipients of the type povidone, corn starch, croscarmellose sodium and stearic acid; (ii) Parasinus contains as active compounds $500 \mathrm{mg} \mathrm{AC}, 3 \mathrm{mg}$ chlorpheniramine maleate, $30 \mathrm{mg}$ pseudoephedrine hydrochloride and excipients of the type pregelatinized starch, talc, povidone, stearic acid, magnesium stearate; and (iii) Pararemin contains as active substances $250 \mathrm{mg}$ AC, $150 \mathrm{mg}$ propyphenazone, $50 \mathrm{mg}$ caffeine and excipients of the type pregelatinized starch (whole), pregelatinized starch (partially), polyvinylpyrrolidone, croscarmellose sodium, stearic acid, isomalt, talc, anhydrous colloidal silicon dioxide.

\subsection{Samples Preparation}

To study the behavior of $\mathrm{AC}$ in the absence of excipients, an aqueous solution of $\mathrm{AC} 0.33 \mathrm{M}$ was prepared. The influence of the alkaline solutions on $A C$ was analyzed using aqueous solutions of $\mathrm{NaOH}$ with various concentrations. Thus, in all experiments, $2 \mathrm{~mL}$ of AC $0.33 \mathrm{M}$ interacted with $1 \mathrm{~mL}$ $\mathrm{NaOH} 10^{-3}, 10^{-2}, 10^{-1}$ or $0.3 \mathrm{M}$.

A tablet of each drug was dispersed into $10 \mathrm{~mL}$ distilled water, under ultrasonication, for $15 \mathrm{~min}$. In order to obtain a clear solution, a successively filtration was carried out. For each drug containing AC, i.e., Paracetamol, Parasinus and Pararemin, $2 \mathrm{~mL}$ of pharmaceutical compounds interacted with $1 \mathrm{~mL} \mathrm{NaOH} 0.3 \mathrm{M}$.

The solid-state interaction of $\mathrm{AC}$ with $\mathrm{NaOH}$, at a non-hydrostatic pressure equal to $0.58 \mathrm{GPa}$ for 5 min has involved: (a) the preparation of three mixtures of $\mathrm{AC}$ and $\mathrm{NaOH}$ as follows: (i) $0.168 \mathrm{~g} \mathrm{AC}$ and $0.04 \mathrm{~g} \mathrm{NaOH}$; (ii) $0.1 \mathrm{~g} \mathrm{AC}$ and $0.2 \mathrm{~g} \mathrm{NaOH}$; and (iii) $0.16 \mathrm{~g} \mathrm{AC}$ and $0.4 \mathrm{~g} \mathrm{NaOH}$. The weight ratios of the three mixtures of $\mathrm{AC}$ and $\mathrm{NaOH}$ are equal to 4.2, 0.5 and 0.4. Homogenization of each mixture of $\mathrm{AC}$ and $\mathrm{NaOH}$ was performed by grinding for $1 \mathrm{~min}$.

\subsection{Photodegradation of Samples}

The samples were exposed successively at UV light, for $140 \mathrm{~min}$, using a mercury-vapors lamp with the power of $350 \mathrm{~W}$, by the selecting with an UG5 filter of the spectral range 200-380 nm, that contains the $\mathrm{Hg}$ spectrum line of high intensity at $253 \mathrm{~nm}$. 


\subsection{Samples Characterization}

PL and PLE spectra of the AC aqueous solution in the absence and in the presence of $\mathrm{NaOH}$ were recorded, in the right-angle geometry, with a Fluorolog-3 spectrophotometer, FL3-2.2.1 model, from Horiba Jobin Yvon, endowed with a $450 \mathrm{~W}$ Xe lamp.

Raman spectra of AC before and after the interaction with $\mathrm{NaOH}$ in the solid state were recorded with a FT Raman spectrophotometer, RFS100S model, from Bruker, endowed with a YAG:Nd laser (excitation wavelength $1064 \mathrm{~nm}$ ).

IR spectra of AC in the initial state and after the interaction with $\mathrm{NaOH}$ in the solid state were recorded with an FTIR spectrophotometer, Vertex 80 model, from Bruker, in the attenuated total reflection geometry.

Additional information concerning the products resulting from the interaction of $\mathrm{AC}$ with $\mathrm{NaOH}$ are shown by X-ray photoelectron spectroscopy (XPS), using a SPECS spectrometer endowed with a PHOBIOS 150 analyzer and an $\mathrm{Al} \mathrm{K} \alpha$ source.

\section{Results}

According to Figure 1a, the PLE spectrum of the AC aqueous solution shows an intense band with the maximum at $317 \mathrm{~nm}$, which is accompanied of another of low intensity at $351 \mathrm{~nm}$. An important decrease in the intensity of the band at $317 \mathrm{~nm}$ is observed to occur from $1.17 \times 10^{6}$ to $6.1 \times 10^{5}$ counts $/ \mathrm{sec}$ when AC is exposed to UV light for 140 min (Figure 1a). The interaction of AC with the $\mathrm{NaOH}$ solutions having concentrations $10^{-3}, 10^{-2}, 10^{-1}$ and $0.3 \mathrm{M}$ induces an up-shift of the PLE band of AC from $317 \mathrm{~nm}$ (Figure 1a) to $323 \mathrm{~nm}$ (Figure 1b), $329 \mathrm{~nm}$ (Figure 1c), $336 \mathrm{~nm}$ (Figure 1d) and $338 \mathrm{~nm}$ (Figure 1e), respectively.

Figure 2 highlights changes in the PL band position and intensity of AC when an interaction of this with the $\mathrm{NaOH}$ solutions having concentrations $10^{-3}, 10^{-2}, 10^{-1}$ and $0.3 \mathrm{M}$ occurs. The PL spectrum of AC shows two emission bands at 361 and $394 \mathrm{~nm}$, the last one having the intensity equal to $3.3 \times 10^{5}$ counts/sec (Figure 2a). As observed in Figure 2a, the exposure of the AC aqueous solution to UV light, for $140 \mathrm{~min}$, leads to a shift of the maximum of emission band from 394 to $427 \mathrm{~nm}$ simultaneously with a decrease in the intensity of this band from $3.3 \times 10^{5}$ to $1.24 \times 10^{5} \mathrm{counts} / \mathrm{sec}$. The interaction of the AC with $\mathrm{NaOH}$ solutions having concentrations $10^{-3}, 10^{-2}, 10^{-1}$ and $0.3 \mathrm{M}$ induces a variation in the intensity of the PL spectrum at cca. $7.3 \times 10^{4}, 1.18 \times 10^{5}, 1.5 \times 10^{4}$ and $1 \times 10^{4}$ counts/sec, respectively. This result can be explained considering the decrease in $\mathrm{AC}$ concentration in the reaction mixture as a consequence of the chemical interaction of $\mathrm{AC}$ with $\mathrm{NaOH}$, according to reaction (2) in Scheme 1. Regardless of the concentration of the $\mathrm{NaOH}$ solution that interacted with the AC, after 140 min of exposure to UV light, it is noticed that the PL spectra shown in Figure 2b-e have maxima at approx. 430-434 nm. According to Figure 2b-e, after $140 \mathrm{~min}$ of exposure to UV light, the AC interacted with the $\mathrm{NaOH}$ solutions having the concentrations equal to $10^{-3}, 10^{-2}, 10^{-1}$ and $0.3 \mathrm{M}$, the intensity of the PL spectra is equal to $6.09 \times 10^{5}, 3.1 \times 10^{5}, 7.5 \times 10^{4}$ and $2.3 \times 10^{4}$ counts/sec, respectively.

A similar behavior with that reported in the case of AC (Figure 1a) takes place by the interaction of $\mathrm{AC}$ with $\mathrm{NaOH} 10^{-3} \mathrm{M}$ (Figure 1b). In this last case, one observes for the PLE band at $323 \mathrm{~nm}$, a decrease in intensity from $1.54 \times 10^{6}$ to $1.22 \times 10^{6}$ counts/sec. For higher $\mathrm{NaOH}$ concentrations such as those in the 0.01-0.3 $\mathrm{M}$ range, an inverse behavior is reported by exposure to UV light of AC solutions which interact with $\mathrm{NaOH}$. By increasing the exposure time at UV light up to $140 \mathrm{~min}$, according to Figure $1 \mathrm{c}-\mathrm{e}$, an intensity increase of the PLE band of AC interacted with $10^{-2}, 10^{-1}$ and $0.3 \mathrm{M} \mathrm{NaOH}$ solutions from $1.64 \times 10^{6}, 5.18 \times 10^{5}$ and $1.32 \times 10^{6} \mathrm{counts} / \mathrm{sec}$ to $4.03 \times 10^{6}, 1.79 \times 10^{7}$ and $1.94 \times 10^{7}$ counts $/ \mathrm{sec}$, respectively, takes place. 

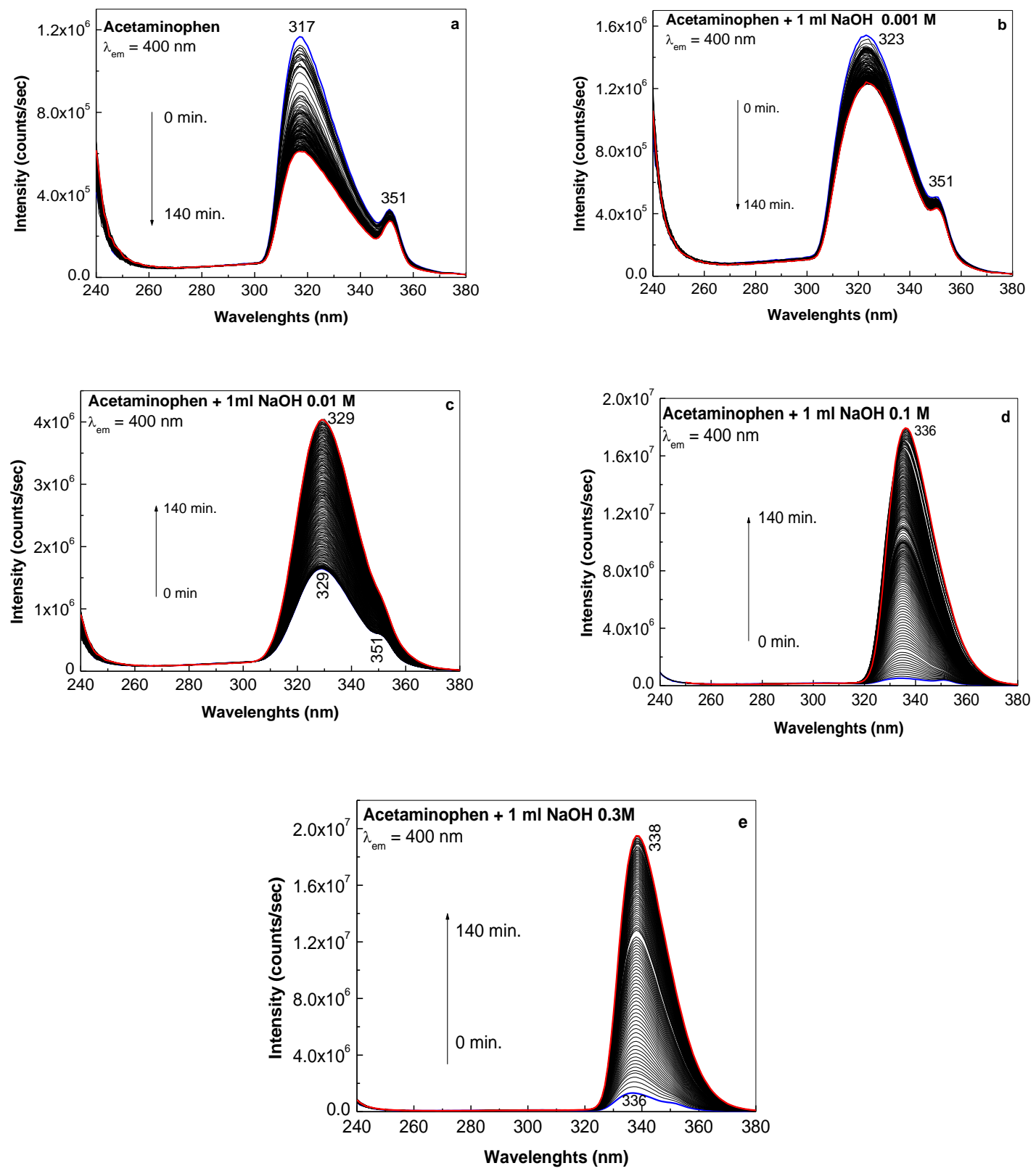

Figure 1. The photoluminescence excitation (PLE) spectra of the aqueous solution of acetaminophen (AC) before (a) and after the interaction with the aqueous solution of $\mathrm{NaOH} 10^{-3} \mathrm{M}(\mathbf{b}), 10^{-2} \mathrm{M}$ (c), $10^{-1} \mathrm{M}(\mathrm{d})$ and $3 \times 10^{-1} \mathrm{M}(\mathrm{e})$. All PLE spectra were recorded at the emission wavelength of $400 \mathrm{~nm}$. Blue and red curves correspond to the first and last spectrum, respectively, of the samples exposed to UV light for 0 and $140 \mathrm{~min}$. Black curves correspond to the intermediate spectra of above samples, each PLE spectrum being collected at $84 \mathrm{~s}$, respectively. 

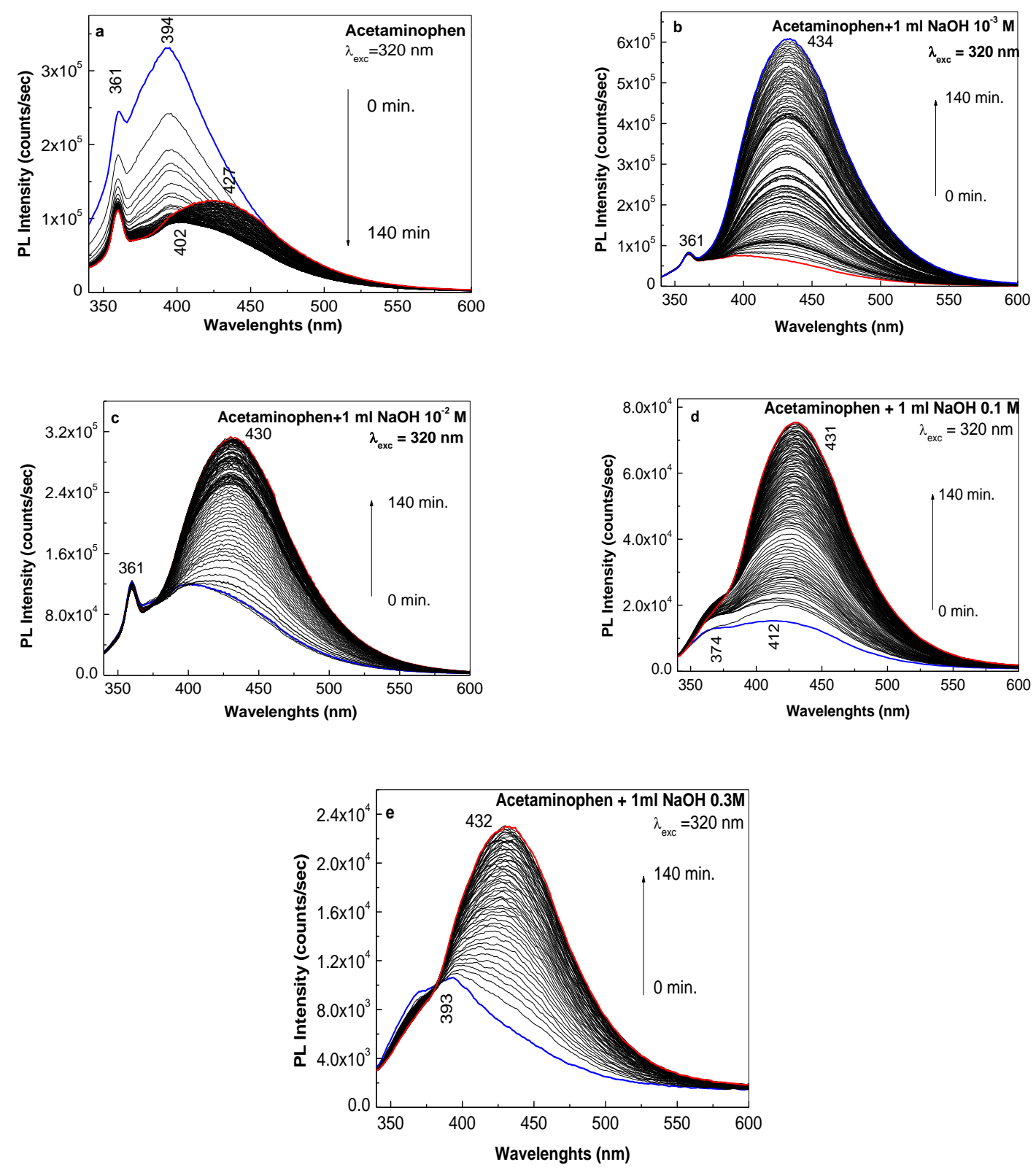

Figure 2. The photoluminescence (PL) spectra of the aqueous solution of AC before (a) and after the interaction with the aqueous solution of $\mathrm{NaOH} 10^{-3}$ (b), $10^{-2}$ (c), $10^{-1}$ (d) and $3 \times 10^{-1} \mathrm{M}$ (e). All PL spectra were recorded at the excitation wavelength of $320 \mathrm{~nm}$. Blue and red curves correspond to the first and last spectrum, respectively, of the samples exposed to UV light for 0 and $140 \mathrm{~min}$. Black curves correspond to the intermediate spectra of above samples, each PL spectrum being collected at $140 \mathrm{~s}$, respectively.

These variations in the PLE and PL spectra of AC are also found in the case of pharmaceutical compounds, after the filtering process. In order to support this statement, Figures $3-5$ show the PLE and PL spectra of the pharmaceutical compounds marketed under the name of Paracetamol, Parasinus and Pararemin before and after their interaction with aqueous solution of $\mathrm{NaOH} 0.3 \mathrm{M}$. 
<smiles>CC(=O)Nc1ccc(O)cc1</smiles><smiles>CCOC(=O)Nc1ccc(O)cc1</smiles>

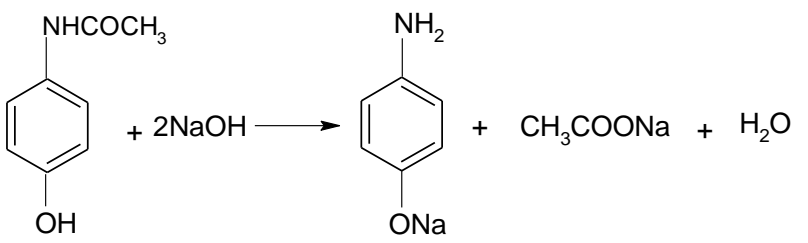

Scheme 1. The chemical reactions of $\mathrm{AC}$ with $\mathrm{H}_{2} \mathrm{O}$ (Equation (1)) and $\mathrm{NaOH}$ (Equation (2)). The interaction of $\mathrm{AC}$ with an excess of $\mathrm{NaOH}$ is described by Equation (3).
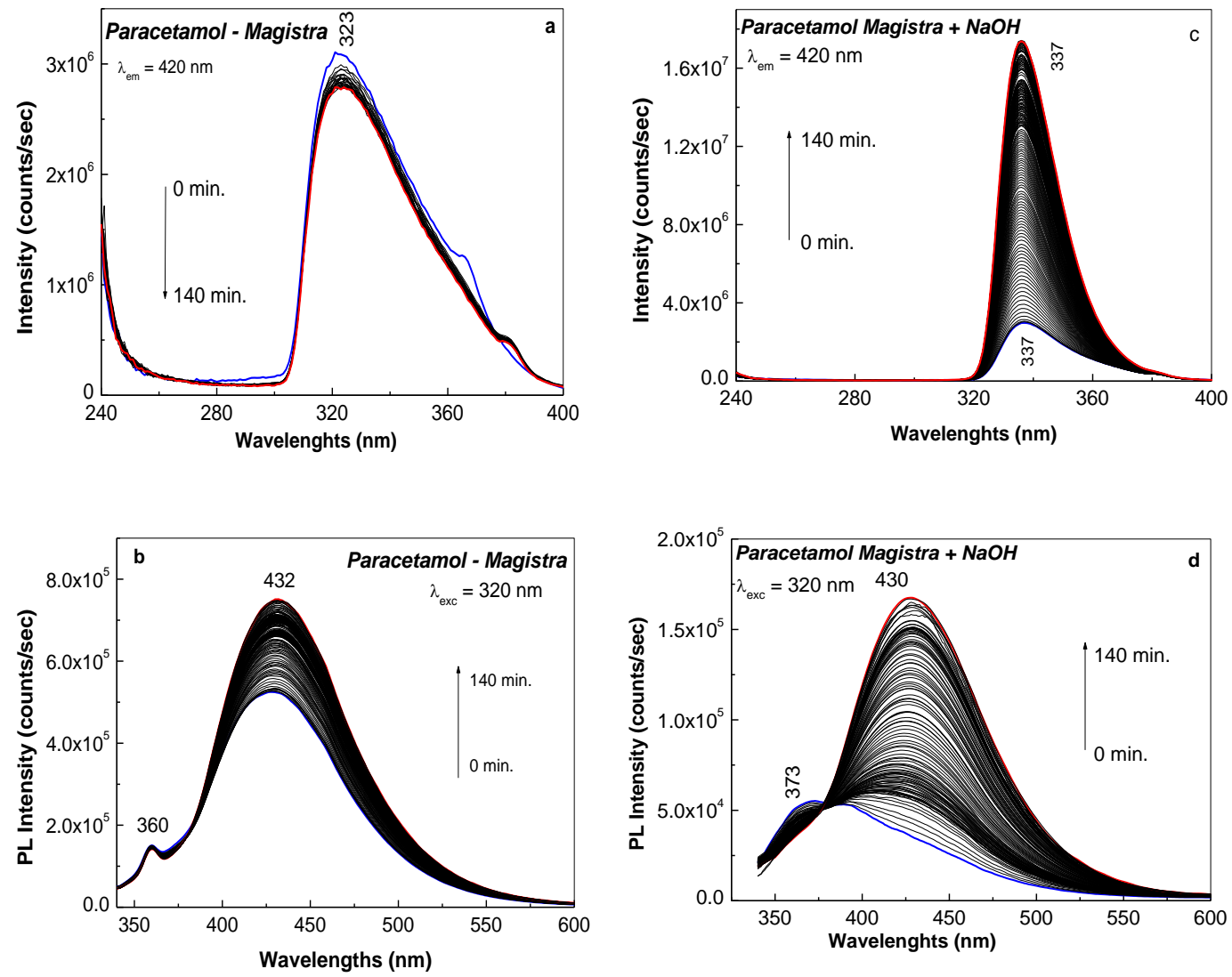

Figure 3. The PLE and PL spectra of the aqueous solution of Paracetamol before $(\mathbf{a}, \mathbf{b})$ and after the interaction with the aqueous solution of $\mathrm{NaOH} 3 \times 10^{-1} \mathrm{M}(\mathbf{c}, \mathbf{d})$. Blue and red curves correspond to the first and last spectrum, respectively, of the samples exposed to UV light for 0 and $140 \mathrm{~min}$. Black curves correspond to the intermediate spectra of above samples, each PLE and PL spectrum being collected at 84 and 140 s, respectively. 

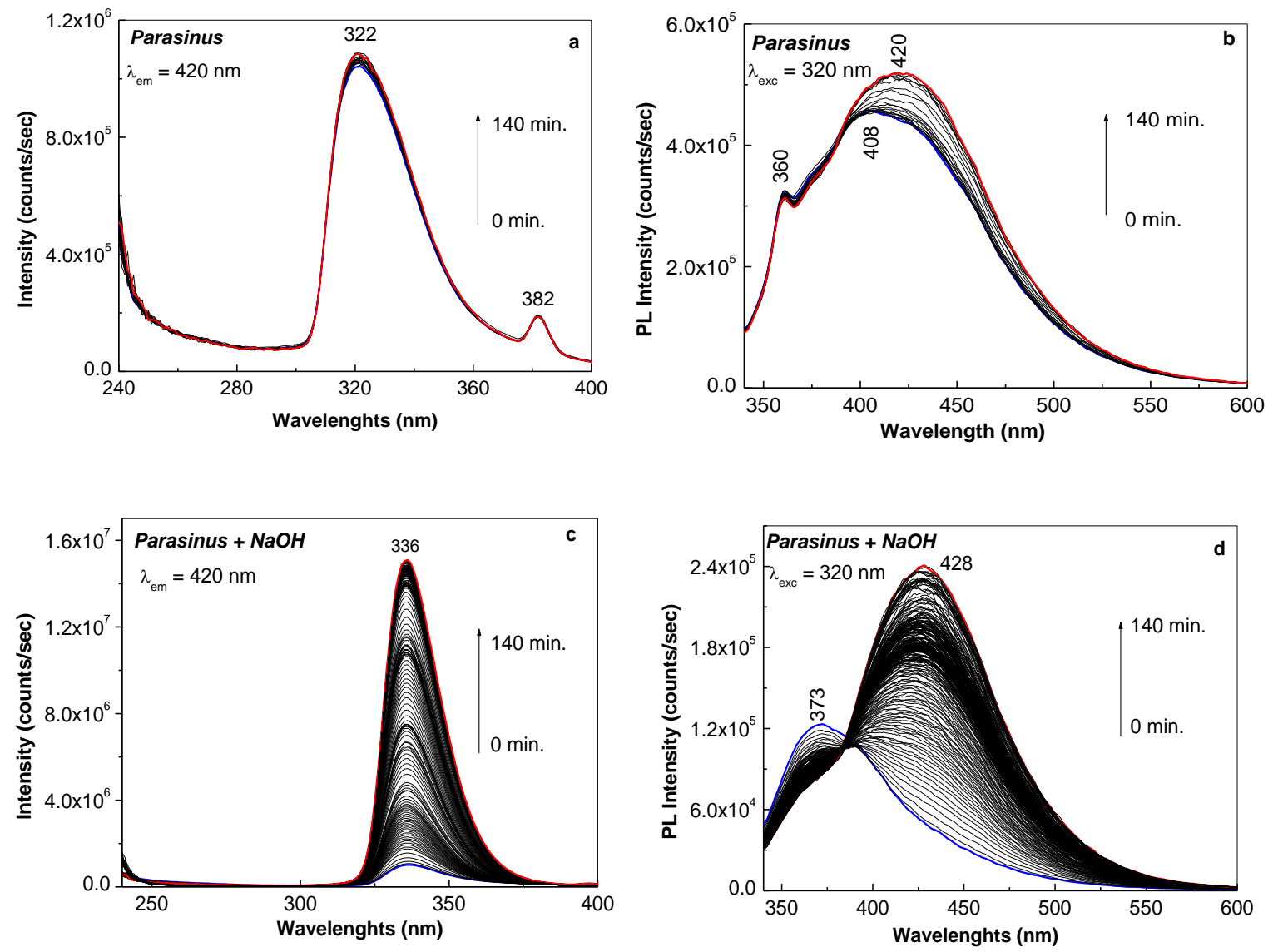

Figure 4. The PLE and PL spectra of the aqueous solution of Parasinus before $(\mathbf{a}, \mathbf{b})$ and after the interaction with the aqueous solution of $\mathrm{NaOH} 3 \times 10^{-1} \mathrm{M}(\mathbf{c}, \mathbf{d})$. Blue and red curves correspond to the first and last spectrum, respectively, of the samples exposed at UV light for 0 and $140 \mathrm{~min}$. Black curves correspond to the intermediate spectra of above samples, each PLE and PL spectrum being collected at 84 and 140 s, respectively.

In the presence of excipients, the band of the AC PLE spectrum is shifted to $323 \mathrm{~nm}$. By exposure to UV light of the aqueous solution of Paracetamol, containing AC and excipients, for $140 \mathrm{~min}$, a variation in the intensity of the PLE band is observed from $3.1 \times 10^{6}$ to $2.7 \times 10^{6}$ counts/sec (Figure 3a). The interaction of the aqueous solution of Paracetamol with $\mathrm{NaOH}$ leads to a shift of the PLE band from $323 \mathrm{~nm}$ (Figure 3a) to $337 \mathrm{~nm}$ (Figure 3c), the subsequent exposure at UV light for 140 min inducing an intensity increase of the PLE band from $2.98 \times 10^{6}$ to $1.74 \times 10^{7}$ counts/sec. Regarding the PL spectrum of Paracetamol, it is observed that the most intense emission band from $394 \mathrm{~nm}$ (Figure 3a) is shifted at $434 \mathrm{~nm}$ (Figure 3b), while the lowest intensity band has the maximum at $361 \mathrm{~nm}$ (Figure 3b), i.e., at the same wavelength as the PL spectrum of AC in the absence of excipients (Figure 3a). By exposure to UV light of the aqueous solution of Paracetamol, for $140 \mathrm{~min}$, a variation of the intensity of the PL band is noticed from $5.22 \times 10^{5}$ to $7.49 \times 10^{5}$ counts/sec. The interaction of Paracetamol with $\mathrm{NaOH}$ induces a down-shift of emission band from $360 \mathrm{~nm}$ (Figure 3b) to $373 \mathrm{~nm}$ (Figure 3d) and subsequent exposure to UV light induces a gradual up-shift of the band from 373 at $430 \mathrm{~nm}$ simultaneous with an intensity increase of this emission band from $5.38 \times 10^{4}$ to $1.7 \times 10^{5}$ counts/sec (Figure $3 \mathrm{~d}$ ). These results confirm that the excipients do not influence the evolution of PLE and PL spectra under UV light. 

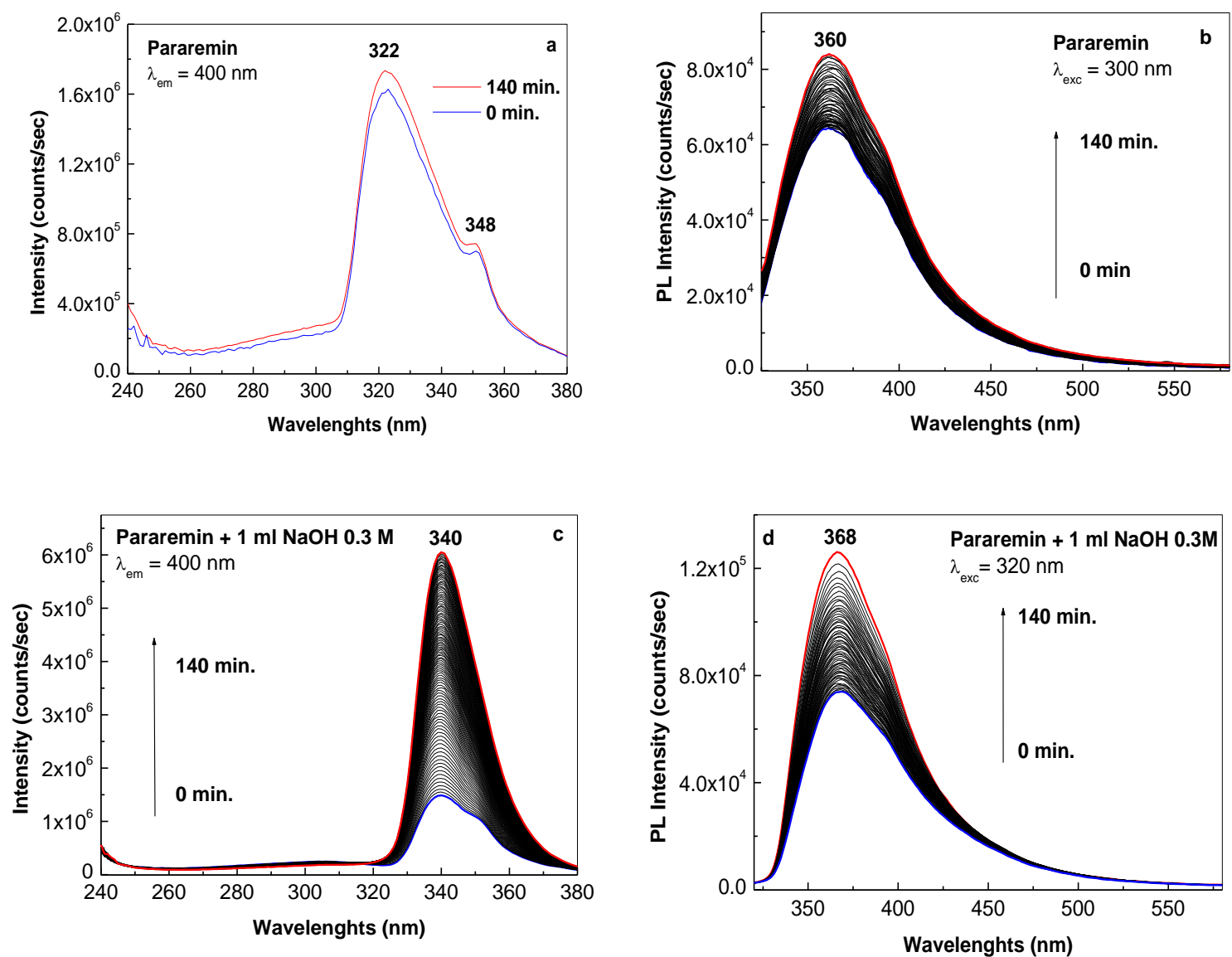

Figure 5. The PLE and PL spectra of the aqueous solution of Pararemin before $(\mathbf{a}, \mathbf{b})$ and after the interaction with the aqueous solution of $\mathrm{NaOH} 3 \times 10^{-1} \mathrm{M}(\mathbf{c}, \mathbf{d})$. Blue and red curves correspond to the first and last spectrum, respectively, of the samples exposed to UV light for 0 and $140 \mathrm{~min}$. Black curves correspond to the intermediate spectra of above samples, each PLE and PL spectrum being collected at 84 and 140 s, respectively.

Table 1 shows the variations induced in the PL and PLE spectra of AC in the presence of other active compounds and excipients, for the particular cases of Parasinus and Pararemin, the results being shown in Figures 4 and 5.

Table 1. The dependence of the maximum and the intensity of PLE and PL spectra of Parasinus and Pararemin as depending on the exposure time to UV light and the interaction with $\mathrm{NaOH}$.

\begin{tabular}{|c|c|c|c|c|c|c|}
\hline Drug Name & $\begin{array}{l}\text { Conc. } \mathrm{NaOH} \\
\text { (M) }\end{array}$ & $\begin{array}{l}\text { Exposure Time at } \\
\text { UV Light (min) }\end{array}$ & $\begin{array}{l}\lambda_{\text {PLE }} \\
(\mathrm{nm})\end{array}$ & $\begin{array}{c}\lambda_{\mathrm{PL}} \\
(\mathrm{nm})\end{array}$ & $\begin{array}{c}\text { I PLE }_{\text {(counts/sec) }} \\
\text { (counts }\end{array}$ & $\begin{array}{c}\mathrm{I}_{\mathrm{PL}} \\
\text { (counts/sec) }\end{array}$ \\
\hline \multirow{4}{*}{ Parasinus } & \multirow{2}{*}{0} & 0 & 322 & 408 & $1.04 \times 10^{6}$ & $4.55 \times 10^{5}$ \\
\hline & & 140 & 322 & 420 & $1.09 \times 10^{6}$ & $5.22 \times 10^{5}$ \\
\hline & \multirow{2}{*}{0.3} & 0 & 336 & 373 & $1.02 \times 10^{6}$ & $1.23 \times 10^{5}$ \\
\hline & & 140 & 336 & 428 & $1.5 \times 10^{7}$ & $2.45 \times 10^{5}$ \\
\hline \multirow{4}{*}{ Pararemin } & \multirow{2}{*}{0} & 0 & 322 & 360 & $1.6 \times 10^{6}$ & $6.4 \times 10^{4}$ \\
\hline & & 140 & 322 & 360 & $1.73 \times 10^{6}$ & $8.4 \times 10^{4}$ \\
\hline & \multirow{2}{*}{0.3} & 0 & 340 & 368 & $1.48 \times 10^{6}$ & $7.36 \times 10^{4}$ \\
\hline & & 140 & 340 & 368 & $6.05 \times 10^{6}$ & $1.27 \times 10^{5}$ \\
\hline
\end{tabular}

The increase in the intensity of the PLE and PL spectra of AC in the presence of other active compounds and excipients (Figure 4; Figure 5) is similar to that reported in the case of pure active 
compounds (Figure 1; Figure 2). To quantify the impact of additional active compounds on AC in the particular case of Parasinus and Pararemin, a careful analysis of Figures 4 and 5 is necessary. In this context, one remarks that: (i) in the initial state, for the two pharmaceutical formulations the maximum of the PLE band is situated at $322 \mathrm{~nm}$, the variation in the intensity of the PLE band, when the samples were exposed to UV light for $140 \mathrm{~min}$, being only of $4.5 \%$ and $7.6 \%$ in the case of Parasinus (Figure $4 \mathrm{a}$ ) and Pararemin (Figure 5a), respectively. These values are lower than those reported in the case of AC and Paracetamol, when one remarks a variation in the intensity of the PLE bands with maxima at 317 and $323 \mathrm{~nm}$ of $47.8 \%$ (Figure $1 \mathrm{a}$ ) and $11.9 \%$ (Figure 3a). Changes in the intensities of the PL bands of Parasinus and Pararemin, with maxima located at 420 and $360 \mathrm{~nm}$ are reported to be equal to $12.8 \%$ (Figure $4 b$ ) and $23.8 \%$ (Figure $5 b$ ), respectively. These variations are smaller compared to those of AC and Paracetamol, for which variations of $\sim 63.6 \%$ and $\sim 30.3 \%$ in intensity of the PL bands with maxima at $394 \mathrm{~nm}$ (Figure 2a) and $432 \mathrm{~nm}$ (Figura 3b), respectively, are reported; ii) after $140 \mathrm{~min}$ of exposure to UV light of the two pharmaceutical products, which were interacted with $1 \mathrm{~mL} \mathrm{NaOH}$ $0.3 \mathrm{M}$, an increase in intensity of PLE bands of Parasinus and Pararemin of $\sim 93.2 \%$ (Figure $4 \mathrm{c}$ ) and $75.5 \%$ (Figure 5c) was reported. These values demonstrate that the presence of chlorpheniramine maleate and pseudoephedrine hydrochloride does not induce additional changes in comparison with those of AC interacting with $\mathrm{NaOH}$, and by successive exposure at UV light for $140 \mathrm{~min}$, an increase in the intensity of the PLE band of $93.2 \%$ (Figure 1e) was noticed. Referring to AC (Figure 1e), the presence of propyphenazone and caffeine induces a slight inhibition of the photodegradation process of AC according to Figure 5c. As increasing the weight of the additional active compounds to AC from 0.6 and $44 \mathrm{wt} . \%$, a reduced variation of the intensity of PL spectra of Paracetamol, Parasinus and Pararemin, from $68 \%$ to $49.8 \%$ and $42 \%$ respectively, is reported. This result confirms that the active compounds contained in Parasinus (chlorpheniramine maleate and pseudoephedrine hydrochloride) and Pararemin, (propyphenazone and caffeine) have the role to inhibit the photodegradation of AC in the alkaline environment.

These changes reported in Figures 1-5 can be explained if we take into account the chemical reactions shown in Scheme 1. According to Scheme 1, depending on the molar ratio between AC and $\mathrm{NaOH}$, i.e., 1:1 (Equation (2)) or 1:2 (Equation (3)), the reaction products correspond to sodium acetate and p-aminophenol or sodium p-aminophenoxide, respectively.

Figures 6 and 7 prove that the chemical reactions of AC with $\mathrm{NaOH}$, shown in Scheme 1, lead to the generation of p-aminophenol and sodium acetate. As shown in Table 2, the main drawback of the IR spectroscopy and Raman scattering in comparison with PL is that these methods do not allow acquiring information in dilute analytes solutions such as those used in the PL studies reported above. Therefore, in the future experiments solid state samples were used to illustrate the interaction of AC with $\mathrm{NaOH}$.

In Figure 6, the black curve shows the Raman spectrum of AC, which is characterized by the lines peaked at 391, 652, 798, 858, 1168, 1238, 1278, 1325, 1562, 1610, 1649, 2931 and $3066 \mathrm{~cm}^{-1}$, that are attributed to the vibrational modes of the deformation of phenyl ring $+\mathrm{C}-\mathrm{H}$ twisting, deformation of phenyl ring, deformation of phenyl ring $+\mathrm{C}-\mathrm{C}$ rocking in amide group, breathing of phenyl ring, $\mathrm{C}-\mathrm{O}-\mathrm{H}$ bending $+\mathrm{C}-\mathrm{C}-\mathrm{H}$ bending in aryl group, $\mathrm{C}-\mathrm{N}$ stretching $+\mathrm{C}-\mathrm{C}$ stretching in amide group, $\mathrm{C}-\mathrm{O}-\mathrm{H}$ bending $+\mathrm{C}-\mathrm{C}-\mathrm{H}$ bending in aryl group $+\mathrm{C}-\mathrm{N}$ rocking in amide group, $\mathrm{C}-\mathrm{O}-\mathrm{H}$ bending $+\mathrm{C}-\mathrm{H}$ rocking $+\mathrm{C}-\mathrm{C}$ stretching in aryl group, $\mathrm{C}-\mathrm{N}-\mathrm{H}$ bending in amide group, $\mathrm{C}-\mathrm{N}$ stretching $+\mathrm{C}-\mathrm{O}$ stretching $+\mathrm{C}-\mathrm{C}$ stretching in aryl group, $\mathrm{C}=\mathrm{O}$ stretching in amide group, symmetrical $\mathrm{C}-\mathrm{H}$ stretching in amide group and asymmetrical C-H stretching in amide group, respectively. [18] The interaction of $\mathrm{AC}$ with $\mathrm{NaOH}$ leads to the variations in Raman spectrum of AC shown in Figure 6 as follows: (i) an up-shift or the Raman line assigned to the vibrational mode of breathing of the phenyl ring from 798 to $804 \mathrm{~cm}^{-1}$ simultaneous with its increase in the intensity; (ii) a gradual decrease in the intensity of the Raman lines situated in the spectral range $1100-1400 \mathrm{~cm}^{-1}$ as well as the Raman lines assigned to the vibrational modes of $\mathrm{C}-\mathrm{N}-\mathrm{H}$ bending in the amide group and $\mathrm{C}=\mathrm{O}$ stretching in the amide group peaked at 1562 and $1649 \mathrm{~cm}^{-1}$, respectively; (iii) a down-shift of the Raman line from 3066 to $3043 \mathrm{~cm}^{-1}$; (iv) a gradual 
increase in the intensity of the Raman line, assigned to the vibrational mode of C-N stretching $+\mathrm{C}-\mathrm{O}$ stretching + C-C stretching in aryl group, which is peaked at $1608 \mathrm{~cm}^{-1}$; and v) a change of the ratio between the intensities of the Raman lines peaked at 1649 and $2931 \mathrm{~cm}^{-1}$ from 4.35 (value reported in the case of $\mathrm{AC}$ ) to 2.69 and 1.12, when samples contain the $\mathrm{AC}: \mathrm{NaOH}$ mass ratios equal to 0.5 and 0.4 , respectively. A puzzling fact is that the aniline-derived compounds and carboxylic acids show in the Raman spectra, lines at $1605[19,20]$ and $2933 \mathrm{~cm}^{-1}$ [21], respectively, very close from those reported in Figure 6. Taking into account these facts, in our opinion, the increase in the relative intensity of the Raman lines at 1608 and $2931 \mathrm{~cm}^{-1}$ originates in the formation of $\mathrm{p}$-aminophenol and sodium acetate, respectively.

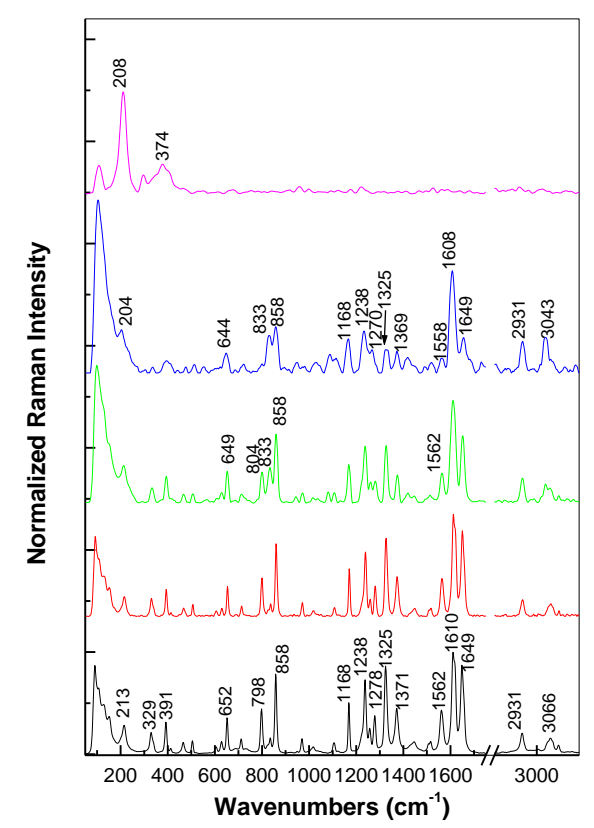

Figure 6. The Raman spectrum of AC (black curve). Red, green and blue curves correspond to the Raman spectra of AC interacted with $\mathrm{NaOH}$, and subsequently exposed to UV light for $140 \mathrm{~min}$, when the AC: $\mathrm{NaOH}$ weight ratio is equal to 4.2, 0.5 and 0.4, respectively. Magenta curve corresponds to the Raman spectrum of $\mathrm{NaOH}$.

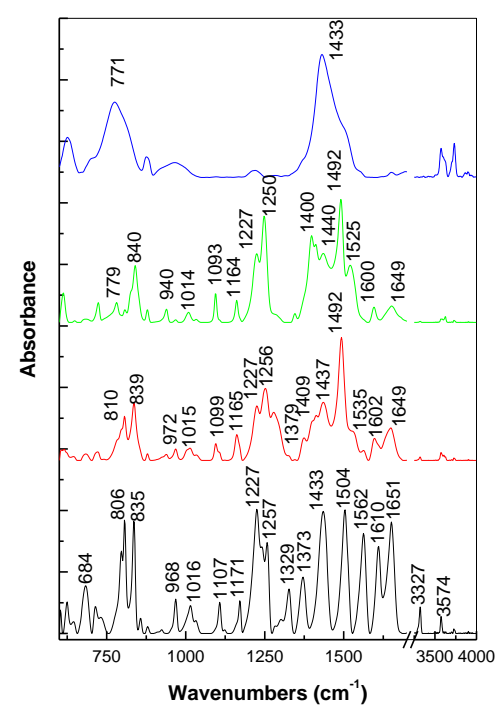

Figure 7. The IR spectra of AC before (black curve) and after the interaction with $\mathrm{NaOH}$, when the AC: $\mathrm{NaOH}$ weight ratio is equal to 4.2 (red curve) and 0.4 (green curve), the samples being subsequently exposed to UV light for $140 \mathrm{~min}$. Blue curve corresponds to the IR spectrum of $\mathrm{NaOH}$. 
Table 2. The most important advantages and drawbacks of the PL in comparison with other methods to assess the photodegradation processes of the pharmaceutical compounds.

\begin{tabular}{|c|c|c|c|}
\hline PL Advantages & PL Drawbacks & PL vs. Another Method & References \\
\hline $\begin{array}{l}\text { Shorter time of collecting results in the } \\
\text { case of the samples in powder state or } \\
\text { as solutions }\end{array}$ & High cost of infrastructure & UV-VIS spectroscopy & This work; [11] \\
\hline $\begin{array}{l}\text { Shorter time of collecting results; no } \\
\text { need additional reagents; the } \\
\text { photodegradation process can be } \\
\text { carried both in-situ and ex-situ }\end{array}$ & $\begin{array}{l}\text { Unseparated products from the reaction } \\
\text { mixture }\end{array}$ & HPLC & This work; [10] \\
\hline $\begin{array}{l}\text { In PL studies, pharmaceutical products } \\
\text { can be both as powder, tablet or dilute } \\
\text { solutions; the photodegradation process } \\
\text { can be analyzed both in-situ and ex-situ. }\end{array}$ & $\begin{array}{l}\text { High cost of infrastructure; higher time } \\
\text { of collecting results; require information } \\
\text { about the chemical structure of } \\
\text { photo-generated products }\end{array}$ & IR spectroscopy & This work \\
\hline $\begin{array}{l}\text { Pharmaceutical products can be } \\
\text { analyzed in the form of dilute solutions; } \\
\text { the photodegradation process can be } \\
\text { analyzed both in-situ and ex-situ. }\end{array}$ & Higher time of collecting results & Raman scattering & This work \\
\hline
\end{tabular}

The IR spectrum represented by black curve in Figure 7 shows IR bands of AC, peaked at $684,806,835,968,1016,1107,1171,1227,1257,1329,1373,1433,1504,1562,1610,1651,3327$ and $3574 \mathrm{~cm}^{-1}$, belonging to the vibrational modes of: the phenyl deformation $+\mathrm{C}-\mathrm{C}$ stretching in amide group, phenyl ring deformation $+\mathrm{C}-\mathrm{C}$ rocking in amide group, $\mathrm{C}-\mathrm{C}-\mathrm{H}$ bending in aryl group, $\mathrm{N}-\mathrm{C}=\mathrm{O}$ bending in amide group, $\mathrm{C}-\mathrm{C}-\mathrm{H}$ bending in amide group, $\mathrm{C}-\mathrm{C}$ rocking $+\mathrm{C}-\mathrm{O}-\mathrm{H}$ bending in aryl group, $\mathrm{C}-\mathrm{O}-\mathrm{H}$ bending $+\mathrm{C}-\mathrm{C}-\mathrm{H}$ bending in aryl group, $\mathrm{C}-\mathrm{N}$ stretching $+\mathrm{C}-\mathrm{C}$ stretching in amide group, $\mathrm{C}-\mathrm{N}-\mathrm{H}$ bending in amide group $+\mathrm{C}-\mathrm{O}$ stretching $+\mathrm{C}-\mathrm{O}-\mathrm{H}$ bending in aryl group, $\mathrm{C}-\mathrm{O}-\mathrm{H}$ bending $+\mathrm{C}-\mathrm{H}$ rocking $+\mathrm{C}-\mathrm{C}$ stretching in aryl group, $\mathrm{C}-\mathrm{H}$ rocking in amide group, $\mathrm{C}-\mathrm{O}-\mathrm{H}$ bending in aryl group $+\mathrm{C}-\mathrm{N}-\mathrm{H}$ bending in amide group, $\mathrm{C}-\mathrm{H}$ rocking in amide group, $\mathrm{C}-\mathrm{N}-\mathrm{H}$ bending in amide group, $\mathrm{C}-\mathrm{N}$ stretching $+\mathrm{C}-\mathrm{O}$ stretching $+\mathrm{C}-\mathrm{C}$ stretching in aryl group, $\mathrm{C}=\mathrm{O}$ stretching in amide group, $\mathrm{N}-\mathrm{H}$ stretching in amide group and $\mathrm{O}-\mathrm{H}$ stretching, respectively. [18] As increasing $\mathrm{NaOH}$ weight that interacts with $\mathrm{AC}$, the following variations are induced in Figure 7: (i) an up-shift of the IR band assigned to the vibrational mode C-C-H bending in aryl group from 835 to $840 \mathrm{~cm}^{-1}$, simultaneous with the decrease of the absorbance of IR band attributed to the phenyl ring deformation $+\mathrm{C}-\mathrm{C}$ rocking in amide group vibrational mode; (ii) the decrease in the absorbance of the IR bands localized in the spectral ranges $900-1200$ and $1373-1379 \mathrm{~cm}^{-1}$ and the down-shift of the IR bands from 968,1107 and $1171 \mathrm{~cm}^{-1}$ to $940,1093,1164 \mathrm{~cm}^{-1}$, respectively; (iii) the increase in the absorbance of the IR bands situated in the spectral range $1400-1500 \mathrm{~cm}^{-1}$ and the down-shift of the IR bands from 1504 and $1562 \mathrm{~cm}^{-1}$ to 1492 and $1525 \mathrm{~cm}^{-1}$; and (iv) the gradual decrease in the absorbance of the IR bands localized in the spectral ranges $1590-1660$ and $3300-3700 \mathrm{~cm}^{-1}$. The absence of the IR bands of 1329 , 1373 and $3327 \mathrm{~cm}^{-1}$ as well as the diminution of the absorbance of IR bands localized in the spectral ranges 1510-1700 and 3500-3600 $\mathrm{cm}^{-1}$ simultaneous with the increase of the absorbance of IR band at $1492 \mathrm{~cm}^{-1}$ attributed to the $\mathrm{C}=\mathrm{C}$ stretching vibrational mode in compounds of the type aniline $[20,22]$ indicate a decrease in the amide group weight as a consequence of the appearance of the amine and carboxylic groups, as shown in Scheme 1. A decrease in the amide group weight after the interaction of AC with $\mathrm{NaOH}$ is also observed by XPS spectroscopy.

According to Figure $8 a_{1}$, the XPS C1s spectrum of $A C$ is characterized by the five peaks at 284, 285, 286, 287.4 and $290 \mathrm{eV}$, assigned to the following bonds: $\mathrm{C}=\mathrm{C}, \mathrm{C}-\mathrm{N}, \mathrm{C}-\mathrm{O}$ in phenolic compounds, $\mathrm{C}=\mathrm{O}$ in amide and $\mathrm{C}=\mathrm{O} / \mathrm{C}=\mathrm{C}$ in aromatic ring, respectively. [23] Two peaks are observed in the N1s spectrum of $\mathrm{AC}$ (Figure $8 \mathrm{~b}_{1}$ ) at 400.4 and $399.7 \mathrm{eV}$ which were attributed to the $-\mathrm{NHCO}$ and $-\mathrm{NH}-$ bonds. [23] In contrast with $\mathrm{AC}$, the following variations are highlighted in Figure 8, as a consequence of the interaction of $\mathrm{AC}$ with $\mathrm{NaOH}$ : (i) an increase of the intensity of the peak at $284 \mathrm{eV}$; (ii) a decrease of the intensity ratio of the peaks at 400.4 and $399.7 \mathrm{eV}$ from 0.34 to 0.23 (Figure $8 \mathrm{~b}_{1}, \mathrm{~b}_{2}$ ), and iii) the presence 
of the Na2s peaks at 62.9 and $64 \mathrm{eV}$ in Figure $8 \mathrm{c}_{2}$, which were attributed to $\mathrm{CH}_{3} \mathrm{COONa}$ and un-reacted $\mathrm{NaOH}[24,25]$, respectively. The Na1s spectrum was also fitted with two components (Figure $8 \mathrm{c}_{1}$ ) - the peak at $1073 \mathrm{eV}$ attributed to $\mathrm{NaOH}$ and another one at $1072 \mathrm{eV}$ attributed to $\mathrm{CH}_{3} \mathrm{COONa}$. Due to the large difference in kinetic energy of the photoelectrons from Na2s and Na1s orbitals, it is proper to assume that the Na1s photoelectrons describe the first layers of the sample's surface while the $\mathrm{Na2s}$ photoelectrons describe the deeper layers. Comparing the peak intensities in the two spectra we can deduce that the unreacted $\mathrm{NaOH}$ is only on the surface of the sample (Figure $8 c_{1}, \mathrm{c}_{2}$ ). All these changes plead for the formation of $\mathrm{p}$-aminophenol and sodium acetate. Based on these results, the most important advantages and drawbacks of the PL in comparison with other methods used in the assessing of the photodegradation processes of the pharmaceutical compounds are shown in Table 2.
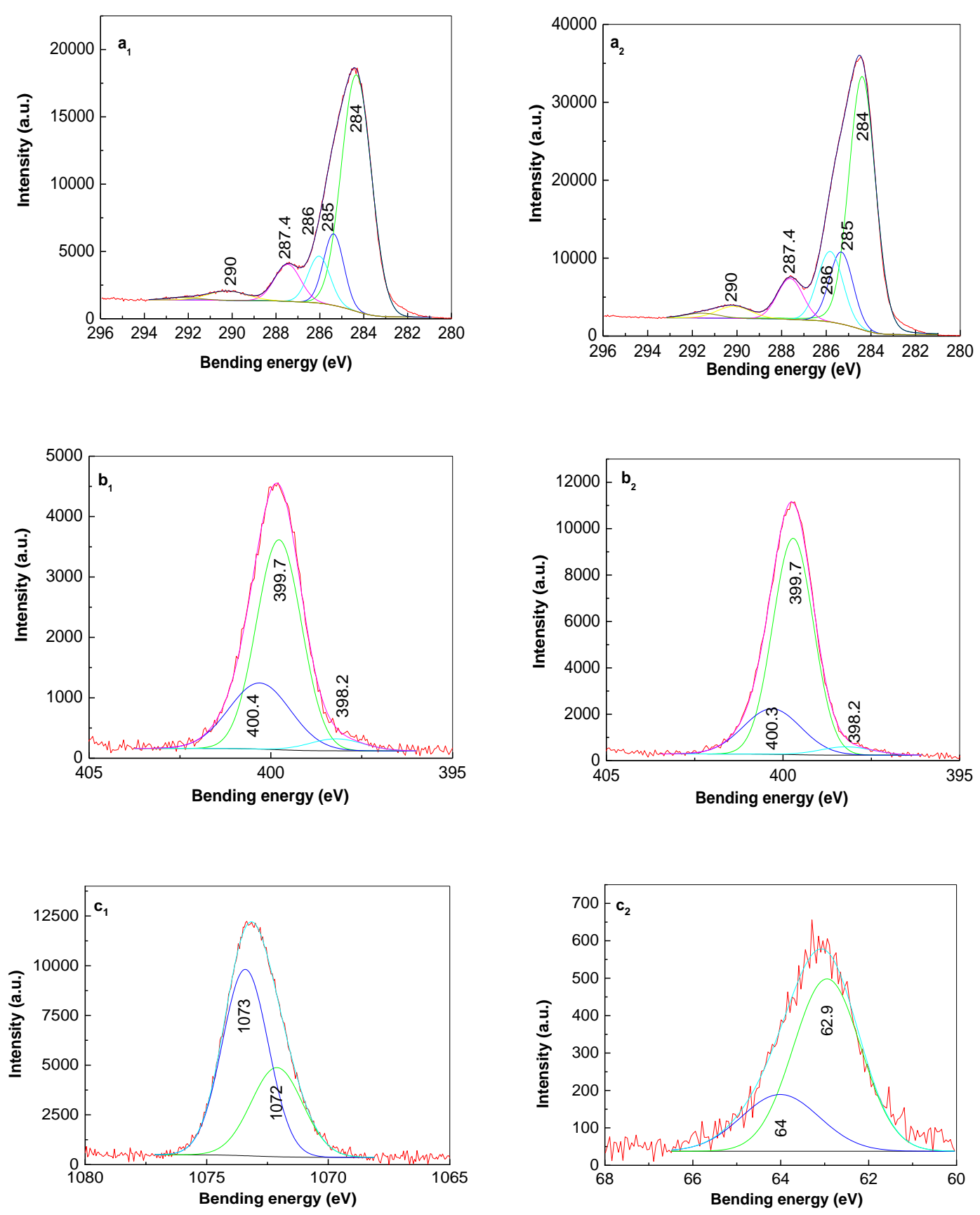

Figure 8. XPS C1s (a) and N1s (b) spectra of AC $\left(\mathbf{a}_{1}, \mathbf{b}_{1}\right)$ as well as AC interacted with $\mathrm{NaOH}\left(\mathbf{a}_{2}, \mathbf{b}_{2}\right)$. $\left(\mathbf{c}_{1}, \mathbf{c}_{2}\right)$ show XPS Na1s and $\mathrm{Na} 2 \mathrm{~s}$ spectra of AC interacted with $\mathrm{NaOH}$. 


\section{Conclusions}

Using photoluminescence (PL), Raman scattering and FTIR spectroscopy, new evidence concerning the interaction of $\mathrm{AC}$ with $\mathrm{NaOH}$ was reported in this work. Our results lead to the following conclusions: (i) photoluminescence represents an alternative method to UV-VIS spectroscopy to monitor the reaction of $\mathrm{AC}$ with $\mathrm{NaOH}$ under $\mathrm{UV}$ light; this reaction is highlighted by the up-shift of the PLE and PL bands from 317 and $394 \mathrm{~nm}$ to 338 and $432 \mathrm{~nm}$, respectively, simultaneous with an intensity increase of these spectra; (ii) the PLE and PL studies have demonstrated that this photochemical reaction is not influenced by the excipients existing in pharmaceutical compounds or the other active compounds such as those used in antipyretic drugs; (iii) the changes invoked in the emission spectra are a consequence of the fact that the interaction of $\mathrm{AC}$ with $\mathrm{NaOH}$ results in the formation of p-aminophenol and sodium acetate; (iv) the main evidence shown in Raman spectra for the formation of p-aminophenol and sodium acetate consist of the presence of the line at $1608 \mathrm{~cm}^{-1}$ and the change of the ratio between the relative intensities of the Raman lines at 1649 and $2931 \mathrm{~cm}^{-1}$ in the favor of the last one; the Raman lines at 1608 and $2931 \mathrm{~cm}^{-1}$ correspond to the $C=C$ stretching vibrational mode in the aniline-derive compound and carboxylic group, respectively; and (v) diminution of the amide group weight in AC as a consequence of the interaction with $\mathrm{NaOH}$ was highlighted in IR spectra by the absence of the bands at 1329, 1373 and $3327 \mathrm{~cm}^{-1}$, the decrease in the absorbance of the IR bands situated in the spectral ranges $1510-1700$ and $3500-3600 \mathrm{~cm}^{-1}$ and the presence of the IR band at $1492 \mathrm{~cm}^{-1}$ attributed to the $\mathrm{C}=\mathrm{C}$ stretching vibrational mode in aniline-derive compounds. A diminution of the amide group simultaneous with the formation of the amine and carboxylic groups, as a consequence of the interaction of $\mathrm{AC}$ with $\mathrm{NaOH}$, was also highlighted by XPS spectroscopy.

Author Contributions: The authors individual contributions are as follows: Conceptualization, M.B. and C.S.; photoluminescence investigations of acetaminophen and the pharmaceutical product market under the name of Paracetamol, M.D.; photoluminescence investigations of Parasinus and Pararemin, A.M.; Raman and FTIR spectroscopy investigation, M.B.; X-ray photoelectron spectroscopy investigation, C.N.; writing一original draft preparation, M.B., C.N.; writing-review and editing, M.B., C.S., A.C.I.; supervision, M.B. All authors have read and agreed to the published version of the manuscript.

Funding: This work was funded by the project co-funded by the European Regional Development Fund under the Competitiveness Operational Program 2014-2020, entitled "Physico-chemical analysis, nanostructured materials and devices for applications in the pharmaceutical field and medical in Romania", financing contract no. 58/05.09.2016 signed by the National Institute of Materials Physics with National Authority for Scientific Research and Innovation as an Intermediate Body on behalf of the Ministry of European Founds as Managing Authority for Operational Program Competitiveness (POC), subcontract D type, no. 2626/04.12.2017, signed by the National Institute of Materials Physics with Bioelectronic SRL.

Conflicts of Interest: The authors declare no conflict of interest. The funders had no role in the design of the study; in the collection, analyses, or interpretation of data; in the writing of the manuscript, or in the decision to publish the results.

\section{References}

1. Haag, G.; Diener, H.C.; May, A.; Meyer, C.; Marck, H.; Straube, A.; Wessely, P.; Evers, S. Self-medication of migraine and tension type headache summary of the evidence based recommendations of the Deutsche Migrane und Kopbschmerzgesellschaft (DMKG), the Deutsch Gesellschaft fur Neurologie (DGN), the Osterreichische Kopfschmerzgesellschaft (OKSG) and the Schweizerische Kopfwegesellschaft (SKG). J. Headache Pain 2011, 12, 201-217. [PubMed]

2. Saragiotto, B.T.; Abdel Shaheed, C. Paracetamol for paint in adults. BMJ 2019, 367, I6693.

3. Hochberg, M.C.; Altman, R.D.; April, K.T.; Benkhalti, M.; Guyatt, G.; McGowan, J.; Towheed, T.; Welch, V.; Wells, G.; Tugwell, P. American College of Rheumantology 2012 recommendations for the use of nonpharmacology and pharmacologic therapies in osteoarthritis of the hand, hip and knee. Arhritis Care Res. 2012, 64, 465-474. [CrossRef]

4. Moore, R.A.; Derry, C. Efficacy of OTC analgesics. Int. J. Clin. Pract. Suppl. 2013, 67, 21-25. [CrossRef] [PubMed] 
5. Perrotd, D.A.; Pira, T.; Goodenough, B.; Champion, G.D. Efficacy and safety of acetaminophen vs. ibuprofen for treating children's pain or fever: A meta-analysis. Arch. Pediatr. Adolesc. Med. 2004, 158, 521-526. [CrossRef]

6. Tan, S.H.S.; Hong, C.C.; Saha, S.; Murphy, D.; Hui, J.H. Medications on COVID-19 patients: Summarizing the current literature from an orthopedic perspective. Int. Orthop. 2020. [CrossRef]

7. Lee, W.M. Acetaminophen (APAP) hepatotoxicity isn't it time for APAP to go away? J. Hepatol. 2017, 67, 1324-1337. [CrossRef] [PubMed]

8. Larson, A.M.; Polson, J.; Fontana, R.J.; Davern, T.J.; Lalani, E.; Hynan, L.S.; Reisch, J.S.; Schiodt, F.V.; Ostapowicz, G.; Shaki, A.O.; et al. The acute live failure study group, acetaminophen induced acute liver failure: Results of a United States multicenter, perspective study. Hepatology 2005, 42, 1364-1372. [CrossRef]

9. Rumack, B.M. Acetaminophen poisoning and toxicity. Pediatrics 1975, 55, 871-876.

10. Bosch, M.E.; Sauche, A.J.R.; Rojas, F.S.; Ojeda, C.B. Determination of paracetamol: Historical evolution. J. Pharm. Biomed. Anal. 2006, 42, 291-321. [CrossRef]

11. Ruiz-Medina, A.; Fernandez-de Cordona, M.L.; Ayora-Canada, M.J.; Pascual-Reguera, M.I.; Molina-Diaz, A. A flow-through solid phase UV spectrophotometer biparameter sensor for the sequential determination of ascorbic acid and paracetamol. Anal. Chim. Acta 2000, 404, 131-139. [CrossRef]

12. Santos, E.D.B.; Lima, E.C.N.L.; De Oliveira, C.S.; Sigoli, F.A.; Mazali, I.O. Fast detection of paracetamol on a fold nanoparticle-chitosan substrate by SERS. Anal. Met. 2014, 6, 3564-3568. [CrossRef]

13. Norrandri, I.; Rakhmana, R. Carbon paste electrode modified with poly(3-aminophenaol) for voltammetric determination of paracetamol. Int. J. Electrochem. Sci. 2012, 7, 4479-4487.

14. Kutluay, A.; Aslanoglu, M. An electrochemical sensor prepared by sonochemical one-pot synthesis of multi-walled carbon nanotube-supported cobalt nanoparticles for the simultaneous determination of paracetamol and dopamine. Anal. Chem. Acta 2014, 839, 59-66. [CrossRef]

15. Adhikari, B.R.; Govindhen, M.; Chen, A. Sensitive detection of acetaminophen with graphene based electrochemical sensor. Electrochim. Acta 2015, 162, 198-204. [CrossRef]

16. Arvand, M.; Gholizadeh, T.M. Simultaneous voltametric determination of tyrosine and paracetamol using a carbon nanotube-graphene nanosheet nanocomposite modified electrode in human blood serum and pharmaceuticals. Colloids Surf. B 2013, 103, 84-93. [CrossRef]

17. Feng, X.; Zhang, Q.; Cong, P.; Zhu, Z. Determination of the paracetamol degradation process with online UV spectroscopic and multivariate curve resolution-Alternating least squares methods comparative validation by HPLC. Anal. Methods 2013, 5, 5286-5293. [CrossRef]

18. Stasilowicz, A.; Mizera, M.; Tykarska, E.; Lewandowska, K.L.; Miklaszewski, A.; Cielecka-Piontek, J. The possibility of using X-ray powder diffraction, infrared and Raman spectroscopy in the study of the identification of structural polymorphs of acetaminophen. Acta Pol. Pharm. Drug Res. 2019, 76, 997-1004. [CrossRef]

19. Brouwer, A.M.; Wilbrandt, R. Vibrational spectra of $N, N$-dimethylaniline and its radical cation. An interpretation based on quantum chemical calculations. J. Phys. Chem. C 1996, 100, 9678-9688. [CrossRef]

20. Shukla, A.R.; Asthana, B.P.; Dongre, N.G.; Pathak, C.M. Infrared and Raman spectra of non-vicinally trisubstituted 2, 5-dimethylaniline and 2-methyl-5-chloroaniline. Vibr. Spectrosc. 1992, 3, 245-253. [CrossRef]

21. Koleva, V.; Stoilova, D. Infrared and Raman studies of the solids in the $\mathrm{Mg}\left(\mathrm{CH}_{3} \mathrm{COO}\right)_{2}-\mathrm{Zn}\left(\mathrm{CH}_{3} \mathrm{COO}\right)_{2}-\mathrm{H}_{2} \mathrm{O}$ system. J. Molec. Struct. 2002, 611,1-8. [CrossRef]

22. Wang, S.; Li, L.; Wang, Q.; Fan, Y.; Shen, J.; Zhang, K.; Yang, L.; Zhang, W. Aniline oligomer-modified graphene for enhanced electrochemical performances. Synth. Met. 2018, 243, 107-114. [CrossRef]

23. Terzyk, A.P. The influence of activated carbon surface chemical composition of the adsorption of acetaminophen (paracetamol) in vitro Part II. TG, FTIR, and XPS analysis of carbons and the temperature dependence of adsorption kinetics at the neutral pH. Colloid Surf. A Physicochem. Eng. Asp. 2001, 177, $23-45$. [CrossRef]

24. Kong, X.; Castarede, D.; Boucly, A.; Artiglia, L.; Ammann, M.; Bartels-Rausch, T.; Thomson, E.S.; Pettersson, J.B.C. Reversibly physisorbed and chemisorbed water on carboxylic salt surfaces under atmospheric conditions. J. Phys. Chem. C. 2020, 124, 5263-5269. [CrossRef] 
25. Citrin, P.H. High-resolution X-ray photoemission from sodium metal and its hydroxide. Phys. Rev. B 1973, 8, 5545-5556. [CrossRef]

Sample Availability: Samples are available from the authors. article distributed under the terms and conditions of the Creative Commons Attribution (CC BY) license (http://creativecommons.org/licenses/by/4.0/). 